\title{
Reference values of exhaled nitric oxide in healthy Asian children aged 5 to 18 years
}

\author{
T-C. Yao*,\#, W-I. Lee*,\#, L-S. Ou*,\#, L-C. Chen*,", K-W. Yeh*,\# and \\ J-L. Huang* ${ }^{\star,}$, for the PATCH Study Group ${ }^{+}$
}

ABSTRACT: This study was undertaken to establish reference values of exhaled nitric oxide fraction $(\mathrm{FeNO})$ and its determinants in healthy Asian children.

693 healthy Asian children aged 5-18 yrs were assessed using a single-breath online FeNO measurement (exhaled flow $50 \mathrm{~mL} \cdot \mathrm{s}^{-1}$ ), questionnaires, anthropometric measurements, spirometry and total and specific immunoglobulin (Ig) $\mathrm{E}$.

Geometric mean $\mathrm{FeNO}$ and the upper $95 \% \mathrm{Cl}$ were $13.7 \mathrm{ppb}$ and $49.7 \mathrm{ppb}$, respectively, for healthy children, and $11.2 \mathrm{ppb}$ and $\mathbf{3 0 . 2} \mathrm{ppb}$, respectively, for those without allergic sensitisation. FeNO was positively associated with age, allergic sensitisation, total $\operatorname{lgE}$, ambient nitric oxide, measurement in the afternoon, and drinking water within $1 \mathrm{~h}$ before testing, and was negatively associated with weight. In healthy children without allergic sensitisation, age was the single best explanatory variable. The FeNO predicted values were 1-2 ppb higher in Asian than in Caucasian children in earlier studies, while the upper $95 \% \mathrm{Cl}$ were 9-10 ppb higher.

In conclusion, the upper limits of normal $F_{\mathrm{eNO}}$ in Asian children depend on age, from $21 \mathrm{ppb}$ in young children to $39 \mathrm{ppb}$ in adolescents. Ethnicity, age, allergic sensitisation, total IgE, ambient nitric oxide, time of testing, drinking water and weight are important determinants.

\section{KEYWORDS: Age, Asian, children, exhaled nitric oxide, prediction equations, reference values}

$\mathbf{T}$ here is growing interest in the potential application of measurement of the exhaled nitric oxide fraction $(\mathrm{FeNO})$ in the diagnosis and management of asthma from research to clinical practice [1-5]. More work is required to determine reference values for appropriate interpretation [1,2] and, although there have been a few studies presenting reference values of $F \mathrm{eNO}$ for children, these have focused on Caucasian populations [6-8]. Current estimates indicate that $\sim 13.2$ million people, or $\sim 4.4 \%$, of the entire USA population are of Asian descent [9]. Ethnic differences of FeNO levels between Caucasians and Asians have been reported in previous Western studies, as FeNO levels are significantly higher in Asian children [7, 8, 10]. Whether FeNO determinants in Asian children also differ from those reported in Caucasian children remains largely unknown.

Nonetheless, it is clear that reference values derived from Caucasian children cannot simply be applied to Asian children. Unfortunately, the small sample sizes of Asian subgroups in previous studies do not provide reliable reference values for clinical application. Thus, there is an unmet need for reference values and determinants of $F$ eNO in Asian children [8]. The present study aimed to establish FeNO reference values and determinants in a large population-based sample of healthy Asian children based on current measurement standards.

\section{METHODS}

\section{Subject recruitment}

The study subjects were enrolled from the Prediction of Allergies in Taiwanese CHildren (PATCH) study, a population-based cohort study that was launched in 2007 to investigate the epidemiology and predictive factors of asthma and allergies in children [11]. The subject flow diagram is presented in figure 1. Of the 1,900 children invited to participate, 1,717 agreed to participate, representing a participation rate of $90.4 \%$. There was no significant difference in terms of age, sex and prevalence of asthma, allergic rhinitis and atopic dermatitis between these 1,717 subjects and the 5,351 children in the original cohort, indicating a sampling cohort representative of the general population. Parents of the 1,717 subjects answered questionnaires regarding demographic data, general health information, and questions on clinical symptoms and diagnosis of allergic diseases. Healthy subjects were selected by including all children who had no chronic illnesses, no history of asthma, allergic rhinitis or atopic dermatitis, and no current or past symptoms of wheeze, rhinitis or eczema, defined by the International Study of Asthma and Allergies in
AFFILIATIONS

${ }^{\star}$ Community Medicine Research Center,

"Dept of Pediatrics, Chang Gung Memorial Hospital at Keelung, Keelung,

\#Division of Allergy, Asthma, and Rheumatology, Dept of Pediatrics, Chang Gung Memorial Hospital and Chang Gung University College of Medicine, Taoyuan, Taiwan. ${ }^{+}$Members of the PATCH (Prediction of Allergies in Taiwanese CHildren) study group are listed in the Acknowledgements section.

\section{CORRESPONDENCE}

$\mathrm{J}$-L. Huang

Division of Allergy, Asthma, and Rheumatology

Dept of Pediatrics

Chang Gung Memorial Hospital

5 Fu-Hsin Street

Kweishan

Taoyuan

Taiwan

E-mail: Iong@adm.cgmh.org.tw

Received:

Jan 242011

Accepted after revision:

May 182011

First published online:

May 262011 


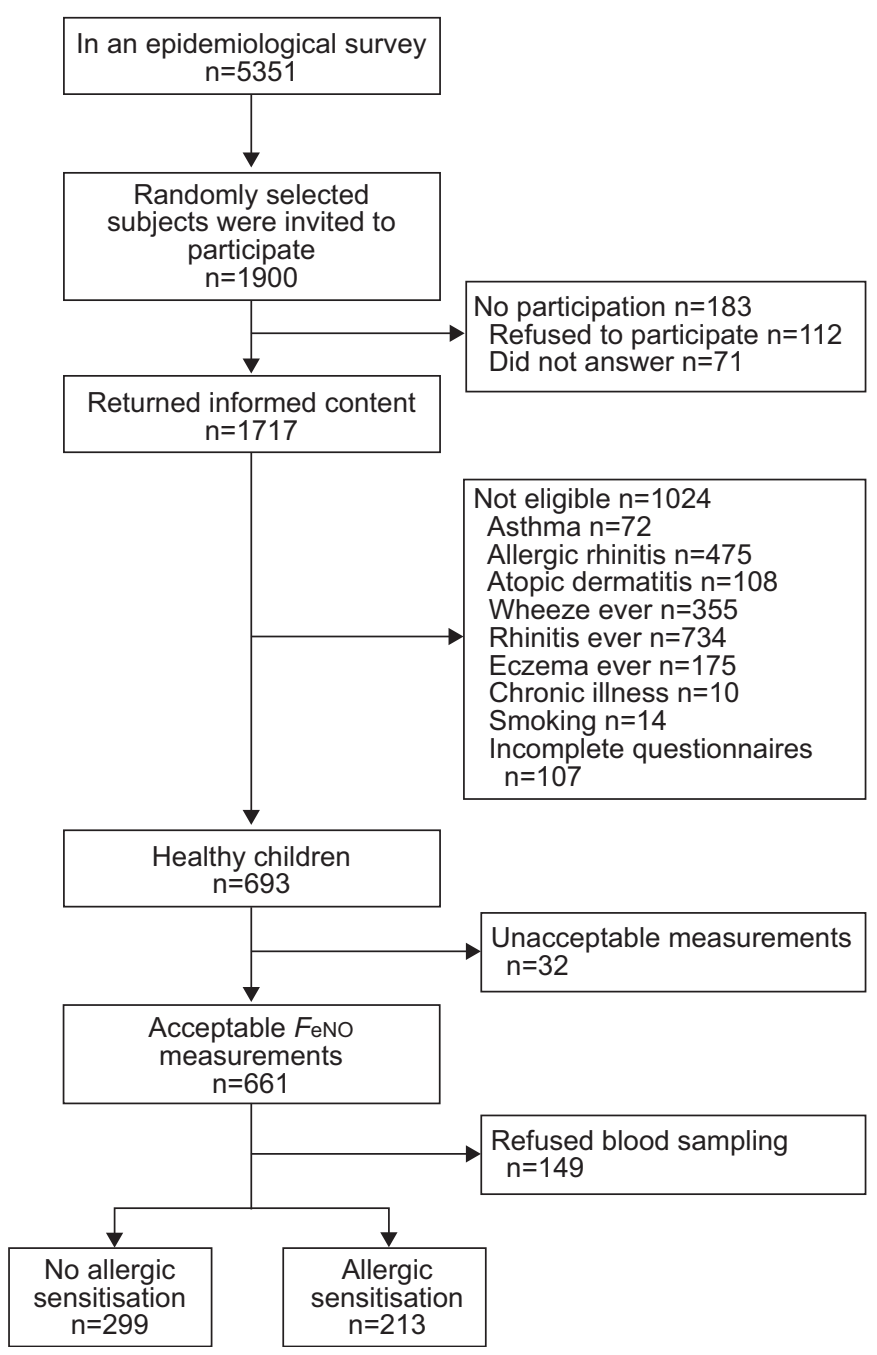

FIGURE 1. Schematic presentation of the recruitment process of the study subjects. FeNO: exhaled nitric oxide fraction.

Childhood (ISAAC) questionnaire [12]. Subjects who smoked or had missing answers on questionnaires were also excluded.

The remaining 693 healthy children (age range 5-18 yrs) who were finally included in this study were all born to parents who were both of Asian descent (mostly Chinese). The Institutional Review Board of Chang Gung Medical Foundation approved the study (96-0370B) and the parents of each subject provided written informed consent.

\section{FeNO and pulmonary function}

The FeNO was measured in all subjects by a single-breath online method using a chemiluminescence analyser (CLD 88sp NO analyser; Eco Medics, Duernten, Switzerland) according to the 2005 American Thoracic Sociey (ATS)/European Respiratory Society (ERS) guidelines [13]. All of the subjects were requested to avoid eating, drinking and strenuous exercise $1 \mathrm{~h}$ before the FeNO measurements. Ambient nitric oxide (NO) and temperature were recorded. A representative tracing of FeNO measurement is shown in figure 2. Subjects inhaled NO-free air through a mouthpiece of the DENOX 88 NO-free air supply module over

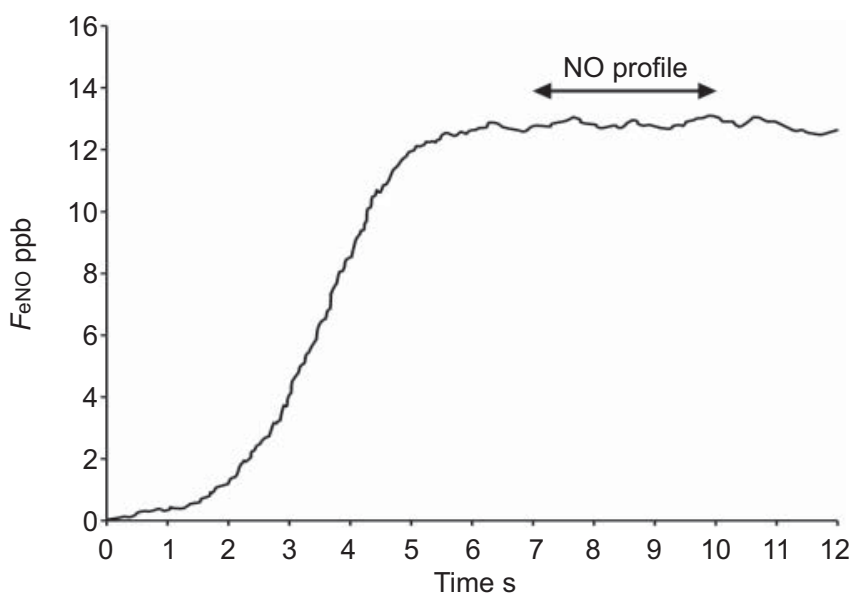

FIGURE 2. Representative tracing of exhaled nitric oxide fraction (FeNO) measurement by a single-breath online method. Exhaled flow rate was $50 \mathrm{~mL} \cdot \mathrm{s}^{-1}$. An exhalation time of $12 \mathrm{~s}$ was used as default. FeNO was calculated during the $7-10 \mathrm{~s}$ (arrow) of exhalation.

a period of $2-3 \mathrm{~s}$ to total lung capacity, minimising contamination of ambient NO. Subjects then exhaled at a flow rate of $50 \mathrm{~mL} \cdot \mathrm{s}^{-1}$ and against enough resistance to maintain an oro-pharyngeal pressure of $5-20 \mathrm{cmH}_{2} \mathrm{O}$, thus preventing contamination of nasal NO. An exhalation time of $12 \mathrm{~s}$ was used as default, while in children aged $<12$ yrs, exhalation time was reduced to $6 \mathrm{~s}$ if needed. Repeated exhalations were performed for a maximum of six attempts in order to obtain three acceptable plateau FeNO values that agree within $10 \%$ or two values within $5 \%$. The mean FeNO was recorded.

After FeNO measurements, the subjects received spirometry (Spirolab II; Medical International Research, Rome, Italy) in accordance with the ATS/ERS recommendations [14] and percentages of the predicted values of pulmonary function variables (i.e. forced vital capacity (FVC), forced expiratory volume in $1 \mathrm{~s}$ (FEV1), FEV1/FVC ratio and forced expiratory flow at $25-75 \%$ of FVC) were calculated [15].

\section{Total and allergen-specific serum immunoglobulin $E$}

The serum level of total immunoglobulin (Ig) E was determined by ImmunoCAP (Phadia, Uppsala, Sweden). Specific IgE was determined by a commercial assay for IgE (ImmunoCAP Phadiatop Infant; Phadia) against the most common inhalant and food allergens (i.e. house dust mite, cat, dog, birch, timothy, ragweed, wall pellitory, egg white, cow's milk, peanut and shrimp). The cut-off values for each ImmunoCAP Phadiatop Infant class $0,1,2,3$ and $>3$ are $0,0.35,0.7,3.5$ and $\geqslant 17.5 \mathrm{kU} \cdot \mathrm{L}^{-1}$, respectively. Values of ImmunoCAP Phadiatop Infant of $\geqslant 0.35 \mathrm{kU} \cdot \mathrm{L}^{-1}$ ( $\geqslant$ class 1$)$ were considered indicative of allergic sensitisation [16].

\section{Statistical analysis}

All data analyses were performed using the SPSS statistical package version 15.0 for Windows (SPSS, Chicago, IL, USA). The FeNO values appeared to be log-normally distributed and were therefore logarithmically transformed for analysis. The results were presented as back-transformed values (i.e. geometric means and $95 \% \mathrm{CI}$ ). Univariate analyses were performed using simple linear regression and unpaired t-tests to assess associations 
between log-transformed FeNO and the following explanatory variables: age, anthropometric measurements, pulmonary function variables, total $\mathrm{IgE}$, ambient $\mathrm{NO}$ and temperature, sex, allergic sensitisation, symptoms of upper respiratory infection (URI) in the past 2 weeks, passive smoking, premature birth, time of testing (i.e. morning (09:00-12:00 h) or afternoon (13:30$16: 30 \mathrm{~h})$ ), and drinking water within $1 \mathrm{~h}$ before testing. Polynomial linear trend analysis was used to examine whether there was a significant linear trend between increasing height of ImmunoCAP Phadiatop Infant class and FeNO.

For multivariate analyses, variables with a $p$-value $<0.1$ in univariate analyses were included in the multiple linear regression model, while a forward stepwise selection with an entry probability of 0.05 and a removal probability of 0.1 from an F-test was used to select the final model. To evaluate the effectiveness of the fitted model in predicting the log-transformed FeNO, adjusted $\mathrm{R}^{2}$ values as a measure of goodness-of-fit of the model was examined. Interactions between variables in the final model were tested and no significant interactions were identified. There was no colinearity in the models as the $\mathrm{R}$ matrix did not include r-values above our threshold of 0.8. Residual analysis with residual plots and normal probability plots of residuals confirmed no violation of the linear regression assumptions. A threshold of $\mathrm{p}<0.05$ was considered statistically significant.

\section{RESULTS}

\section{Subject characteristics}

Acceptable FeNO measurements were available in 661 of 693 study subjects ( $95.4 \%$; table 1 ). The relatively lower proportion of males in this cohort was attributed to the exclusion of children with allergic diseases, which were more common in males in the general population. Acceptable pulmonary function tests and total and specific IgE levels were available in 650 (98.3\%) and 512 $(77.5 \%)$ subjects, respectively.

\section{All healthy Asian children as a group}

The geometric mean FeNO level in the entire healthy children population was $13.7 \mathrm{ppb}$ and the upper $95 \%$ CI was $49.7 \mathrm{ppb}$. Six children (four males) were outliers (defined by box plot outlier rules) for FeNO, predominantly those with allergic sensitisation (all four received blood sampling). Two outliers reported recent symptoms of URI: one had allergic sensitisation and the other

TABLE 1 Characteristics of study subjects

\begin{tabular}{|c|c|c|c|c|c|}
\hline & \multirow[t]{2}{*}{ All } & \multicolumn{4}{|c|}{ Age yrs } \\
\hline & & $5-7$ & $8-10$ & $11-13$ & $14-17$ \\
\hline Subjects $\mathrm{n}$ & 661 & 150 & 231 & 204 & 76 \\
\hline \multicolumn{6}{|l|}{ Continuous variable } \\
\hline \multicolumn{6}{|l|}{ Anthropometric measurement } \\
\hline $\mathrm{BMI} \mathrm{kg} \cdot \mathrm{m}^{-2}$ & $18.3 \pm 3.5$ & $16.7 \pm 2.8$ & $17.6 \pm 2.8$ & $19.4 \pm 3.9$ & $20.7 \pm 3.7$ \\
\hline Body surface area $\mathrm{m}^{2}$ & $1.17 \pm 0.26$ & $0.91 \pm 0.13$ & $1.07 \pm 0.14$ & $1.32 \pm 0.21$ & $1.55 \pm 0.16$ \\
\hline \multicolumn{6}{|l|}{ Pulmonary function } \\
\hline FVC L & $2.03 \pm 0.65$ & $1.44 \pm 0.27$ & $1.81 \pm 0.33$ & $2.32 \pm 0.48$ & $3.06 \pm 0.63$ \\
\hline FEV 1 L & $1.77 \pm 0.55$ & $1.26 \pm 0.22$ & $1.57 \pm 0.26$ & $2.03 \pm 0.39$ & $2.68 \pm 0.52$ \\
\hline $\mathrm{FEV}_{1 / / F V C}$ ratio \% & $87.7 \pm 6.0$ & $87.4 \pm 6.6$ & $87.3 \pm 5.7$ & $88.3 \pm 5.8$ & $88.0 \pm 5.9$ \\
\hline FEF25-75\% \% pred & $90.7 \pm 19.5$ & $86.8 \pm 20.8$ & $91.0 \pm 18.4$ & $93.7 \pm 19.8$ & $89.4 \pm 18.3$ \\
\hline Total lgE kU. $\mathrm{L}^{-1}$ & $166.1 \pm 391.1$ & $144.1 \pm 231.4$ & $189.0 \pm 523.4$ & $138.0 \pm 272.6$ & $222.3 \pm 468.6$ \\
\hline Ambient nitric oxide ppb & $2.51 \pm 2.86$ & $2.41 \pm 2.46$ & $2.19 \pm 2.05$ & $3.03 \pm 3.84$ & $2.31 \pm 2.46$ \\
\hline Ambient temperature ${ }^{\circ} \mathrm{C}$ & $23.0 \pm 5.9$ & $23.0 \pm 5.6$ & $24.0 \pm 5.8$ & $23.7 \pm 5.4$ & $18.5 \pm 6.1$ \\
\hline \multicolumn{6}{|l|}{ Categorical variable } \\
\hline Males & 39.5 & 44.7 & 38.5 & 40.7 & 28.9 \\
\hline Allergic sensitisation ${ }^{\#}$ & 41.6 & 48.3 & 40.9 & 39.8 & 35.6 \\
\hline Recent URI symptoms" & 29.4 & 34.0 & 27.1 & 26.3 & 35.2 \\
\hline Passive smoking & 53.2 & 52.4 & 51.1 & 54.9 & 57.1 \\
\hline Premature birth & 5.2 & 4.1 & 6.8 & 5.6 & 1.4 \\
\hline Time of testing (afternoon) & 48.3 & 42.0 & 52.4 & 45.6 & 55.3 \\
\hline
\end{tabular}

Data are presented as mean \pm SD or \%, unless otherwise stated. BMI: body mass index; FVC: forced vital capacity; FEV 1 : forced expiratory volume in 1 s; FEF25-75\%: forced expiratory flow at $25-75 \%$ of FVC; \% pred: \% predicted; IgE: immnoglobulin E; URI: upper respiratory infection. ${ }^{\text {* }}$ : defined as a value of ImmunoCAP Phadiatop Infant (Phadia, Uppsala, Sweden) of $\geqslant 0.35 \mathrm{kU} \cdot \mathrm{L}^{-1} ;{ }^{\bullet}$ : symptoms in past 2 weeks; ${ }^{+}$: drinking water within $1 \mathrm{~h}$ before testing. 


\begin{tabular}{|c|c|c|c|c|c|}
\hline TABLE 2 & \multicolumn{5}{|c|}{$\begin{array}{l}\text { Characteristics and factors associated with } \\
\text { exhaled nitric oxide fraction in healthy Asian } \\
\text { children by univariate analyses }\end{array}$} \\
\hline \multicolumn{2}{|c|}{ Continuous variable } & Mean $\pm S D$ & $\mathbf{n}$ & $\mathbf{R}$ & p-value \\
\hline \multicolumn{2}{|l|}{ Age yrs } & $10.2 \pm 2.6$ & 661 & 0.176 & $<0.001$ \\
\hline \multicolumn{6}{|c|}{ Anthropometric measurement } \\
\hline \multicolumn{2}{|l|}{ Height cm } & $138.2 \pm 14.7$ & 661 & 0.136 & 0.001 \\
\hline \multicolumn{2}{|l|}{ Weight kg } & $36.1 \pm 13.0$ & 661 & 0.073 & 0.062 \\
\hline \multicolumn{2}{|c|}{$\mathrm{BMI} \mathrm{kg} \cdot \mathrm{m}^{-2}$} & $18.3 \pm 3.5$ & 661 & -0.015 & 0.699 \\
\hline \multicolumn{2}{|c|}{ Body surface area $\mathrm{m}^{2}$} & $1.17 \pm 0.26$ & 661 & 0.092 & 0.018 \\
\hline \multicolumn{6}{|c|}{ Pulmonary function } \\
\hline \multicolumn{2}{|c|}{ FVC L } & $2.03 \pm 0.65$ & 650 & 0.102 & 0.009 \\
\hline \multicolumn{2}{|l|}{ FEV 1 L } & $1.77 \pm 0.55$ & 650 & 0.119 & 0.002 \\
\hline \multicolumn{2}{|c|}{$\mathrm{FEV}_{1} / \mathrm{FVC}$ ratio $\%$} & $87.7 \pm 6.0$ & 650 & 0.073 & 0.064 \\
\hline \multicolumn{2}{|c|}{ FEF $25-75 \% L \cdot S^{-1}$} & $2.20 \pm 0.74$ & 650 & 0.125 & 0.001 \\
\hline \multicolumn{2}{|c|}{ FVC \% pred } & $90.5 \pm 11.3$ & 650 & -0.104 & 0.008 \\
\hline \multicolumn{2}{|c|}{ FEV $1 \%$ pred } & $89.9 \pm 10.3$ & 650 & -0.065 & 0.096 \\
\hline \multicolumn{2}{|c|}{ FEV1/FVC \% pred } & $97.7 \pm 6.7$ & 650 & 0.091 & 0.020 \\
\hline \multicolumn{2}{|c|}{ FEF25-75\% \% pred } & $90.7 \pm 19.5$ & 650 & 0.010 & 0.796 \\
\hline \multicolumn{2}{|c|}{ Total IgE kU $\cdot \mathrm{L}^{-1}$} & $166.1 \pm 391.1$ & 512 & 0.299 & $<0.001$ \\
\hline \multicolumn{2}{|c|}{ Ambient nitric oxide ppb } & $2.51 \pm 2.86$ & 661 & 0.087 & 0.026 \\
\hline \multicolumn{2}{|c|}{ Ambient temperature ${ }^{\circ} \mathbf{C}$} & $23.0 \pm 5.9$ & 661 & -0.009 & 0.822 \\
\hline
\end{tabular}

BMI: body mass index; FVC: forced vital capacity; FEV1: forced expiratory volume in $1 \mathrm{~s}$; FEF25-75\%: forced expiratory flow at $25-75 \%$ of FVC; $\%$ pred: $\%$ predicted; IgE: immunoglobulin E. p-values in bold are significant.

drank water within $1 \mathrm{~h}$ before testing. These outliers were unlikely to result from an error in data recording and were therefore not excluded from the analyses. However, the six outliers were not included in the calculation of FeNO reference values in healthy children without allergic sensitisation because four of them had allergic sensitisation and the other two refused blood sampling.

Univariate analyses (tables 2 and 3) showed that age, height, body surface area, several pulmonary function variables, total IgE and ambient NO were significantly correlated with FeNO levels (all $\mathrm{p}<0.05)$. There were significant differences in FeNO levels among subjects grouped by allergic sensitisation $(p<0.001)$, time of testing $(p=0.006)$ or drinking water within $1 \mathrm{~h}$ before testing $(\mathrm{p}=0.006)$. Interestingly, there was a significant positive correlation between FeNO level and increasing height of ImmunoCAP Phadiatop Infant class (polynomial linear trend analysis $\mathrm{p}<0.001$; fig. 3).

Multivariate analyses demonstrated that FeNO was positively associated with age, allergic sensitisation, total $\operatorname{IgE}$, ambient $\mathrm{NO}$, measurement in the afternoon and drinking water within $1 \mathrm{~h}$ before testing, and was negatively associated with weight (equation 1 ; table 4). Altogether, these factors accounted for $21.7 \%$ of total variability.

\section{Healthy Asian children without allergic sensitisation}

The status of allergic sensitisation was taken into account in 512 of 661 subjects who received blood sampling. The geometric mean FeNO and the upper $95 \% \mathrm{CI}$ in the subgroup of 213 healthy subjects with allergic sensitisation were $17.7 \mathrm{ppb}$ and $74.8 \mathrm{ppb}$, respectively. In contrast, the geometric mean FeNO and the upper $95 \%$ CI in 299 healthy subjects without allergic sensitisation were $11.2 \mathrm{ppb}$ and $30.2 \mathrm{ppb}$, respectively. In the stepwise regression analysis, age appeared to be the best independent variable explaining variability of FeNO. After introducing age into the model and adjusting for other variables, no other factors had significant and independent effects on FeNO. Thus, the regression equation finally selected for healthy subjects without allergic sensitisation was a simple model that had age as the single best explanatory variable (equation 2, table 4):

$$
\text { Ln } F \text { eNO=1.933+age }(\mathrm{yrs}) \times 0.046 .
$$

In order to facilitate comparability of the results to those reported in Caucasian children, another regression equation was presented by further excluding 79 subjects who reported symptoms of URI in the past 2 weeks $(n=220$; equation 3 , table 4$)$ :

$$
\text { Ln } F \text { eNO=1.892+age (yrs) } \times 0.048
$$

The predicted FeNO values and the upper 95\% CI based on equation 3 are presented in figure 4 . For comparison, the results are shown with data in a sample of healthy nonatopic Caucasian children [6]. Compared with recent data of Caucasian children [6, $7]$, the predicted FeNO values were $\sim 1-2$ ppb higher in healthy children without allergic sensitisation in the study population, and the upper $95 \%$ CI were 9-10 ppb higher in the current study.

TABLE 3 Characteristics and factors associated with exhaled nitric oxide fraction ( $F$ eNO) in healthy Asian children by univariate

\begin{tabular}{|c|c|c|c|c|c|}
\hline \multirow[t]{2}{*}{ Categorical variable } & \multirow[t]{2}{*}{ Subjects $\%$} & \multirow[t]{2}{*}{ Subjects $n$ /total $n$} & \multicolumn{2}{|c|}{$\mathrm{FeNO}^{\#} \mathrm{ppb}$} & \multirow[t]{2}{*}{ p-value } \\
\hline & & & Yes & No & \\
\hline Males & 39.5 & $261 / 661$ & $13.5(12.4-14.6)$ & $13.9(13.0-14.8)$ & 0.567 \\
\hline Allergic sensitisation & 41.6 & $213 / 512$ & $17.7(16.0-19.5)$ & $11.2(10.6-11.9)$ & $<0.001$ \\
\hline Recent URI symptoms ${ }^{+}$ & 29.4 & $187 / 637$ & $14.3(12.9-15.7)$ & $13.5(12.7-14.3)$ & 0.347 \\
\hline Passive smoking & 53.2 & $339 / 637$ & $14.1(13.2-15.1)$ & $13.3(12.3-14.4)$ & 0.234 \\
\hline Premature birth & 5.2 & $33 / 634$ & $14.0(11.3-17.3)$ & $13.7(13.0-14.5)$ & 0.853 \\
\hline Afternoon testing $^{5}$ & 48.3 & $319 / 661$ & $14.7(13.7-15.8)$ & $12.8(11.9-13.8)$ & 0.006 \\
\hline Drinking $^{f}$ & 2.4 & $16 / 661$ & $21.4(14.1-32.3)$ & $13.5(12.9-14.2)$ & 0.006 \\
\hline
\end{tabular}
analyses

URI: upper respiratory infection. ${ }^{*}$ : presented as the geometric mean (95\% Cl); ${ }^{\bullet}$ : defined as a value of ImmunoCAP Phadiatop Infant (Phadia, Uppsala, Sweden) of $\geqslant 0.35 \mathrm{kU} \cdot \mathrm{L}^{-1}{ }^{+}{ }^{+}$: symptoms in past 2 weeks; ${ }^{\S}$ : compared with morning; ${ }^{f}$ : drinking water within $1 \mathrm{~h}$ before testing. $\mathrm{p}$-values in bold are significant. 


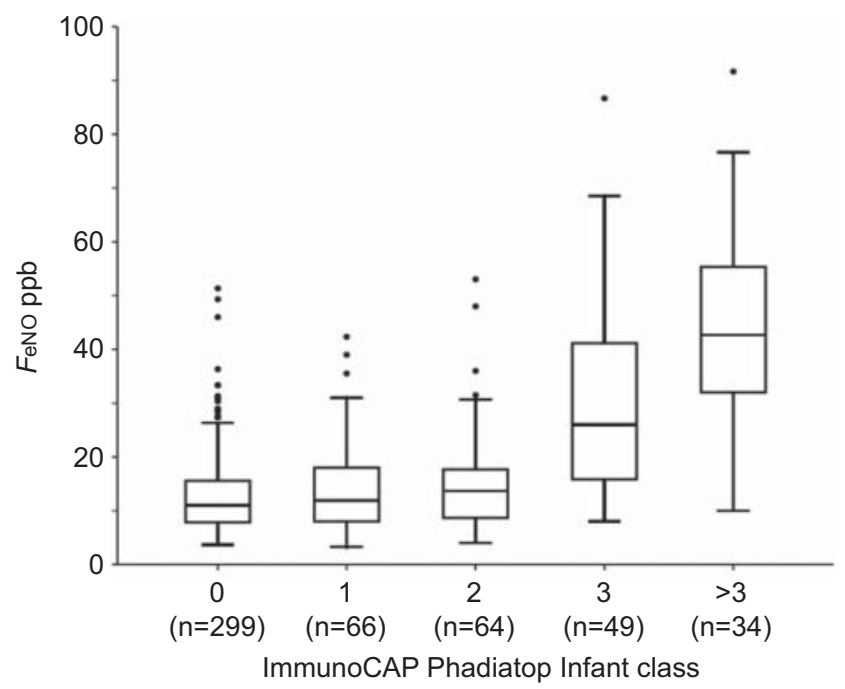

FIGURE 3. Box plots showing median and interquartile ranges of exhaled nitric oxide fraction ( $\mathrm{FeNO}$ ) by ImmunoCAP Phadiatop Infant (Phadia, Uppsala, Sweden) classes. The cut-off values for each ImmunoCAP Phadiatop Infant class 0, 1, 2, 3 and $>3$ were $0,0.35,0.7,3.5$ and $\geqslant 17.5 \mathrm{kU} \cdot \mathrm{L}^{-1}$, respectively. Dots beyond the bounds of the whiskers denote outliers. An increasing height of ImmunoCAP Phadiatop Infant class was significantly associated with $\mathrm{FeNO}$ levels by polynomial linear trend analysis $(p<0.001)$.

\section{DISCUSSION}

This is the largest study to date of FeNO in healthy Asian children that defines the upper limit of normal (ULN; defined as the upper $95 \% \mathrm{CI}$ in accordance with earlier studies $[6,7])$ for FeNO, which is age dependent. The upper limit ranges from $21 \mathrm{ppb}$ at 5 yrs of age to $39 \mathrm{ppb}$ at $18 \mathrm{yrs}$. Importantly, the present study identifies that the predicted FeNO values in Asian children in the current population are $\sim 1-2 \mathrm{ppb}$ higher than in Caucasian children in earlier studies $[6,7]$ and the ULNs are $\sim 9-10 \mathrm{ppb}$ higher in the current study. MALMBERG et al. [6] have established a regression equation for FeNO from 114 nonatopic, nonsmoking healthy Caucasian children aged 6.9-15.7 yrs in Finland. Therefore, direct comparison with the reference equation from the present study is possible. The ULNs for FeNO in Asian children in this study are $\sim 9 \mathrm{ppb}$ higher than in Caucasian children in the study by MALMBERG et al. [6]. BUCHVALD et al. [7] have established reference values of FeNO from 405 healthy children aged 4-17 yrs (mostly Caucasians) in Europe and the USA. The ULN for FeNO ranges 15$25 \mathrm{ppb}$ depending on age and self-reported atopy [7], with an $\sim 10$-ppb difference compared with the corresponding values in the current study. BuCHVALD et al. [7] have also noted significantly higher FeNO levels in non-Caucasian children (Asians, AfricanAmericans and Hispanics). Consistent with the current study, FeNO levels in a relatively small group of Japanese children aged 10-12 yrs who were nonatopic and had never experienced wheeze [17], were also higher than those of Caucasian children [6-8]. However, a recent study reports that FeNO reference values in healthy Japanese adults [18] were similar to those of Caucasians [19-21]. Thus, whether or not ethnic differences of FeNO levels between Caucasians and Asians are restricted to children warrants further study.

Explanations for the observed higher levels, and particularly higher variation of $F \mathrm{eNO}$, in Asian children in the current study than in Caucasian children in previous studies still need to be identified. It is important to recognise that only a small proportion of the variability of FeNO values can be explained here and in prior population-based studies $[6,21,22]$ by determinants of FeNO identified so far, leading many to question how the remaining "missing variability" of FeNO can be explained. Interestingly, a population-based study of twins suggests that genetic effects account for most of the FeNO variations, and that environmental factors have a minor role [23]. Moreover, variants in the NO synthesis pathway genes contribute to differences in FeNO levels in

\begin{tabular}{|c|c|c|c|c|c|c|}
\hline \multirow[t]{2}{*}{ Variable } & \multirow{2}{*}{\multicolumn{2}{|c|}{$\begin{array}{c}\text { Equation } 1^{\#} \\
\text { All healthy subjects }\end{array}$}} & \multicolumn{2}{|c|}{ Equation $2^{\#}$} & \multicolumn{2}{|c|}{ Equation $3^{\#}$} \\
\hline & & & \multicolumn{2}{|c|}{ Subjects without allergic sensitisation ${ }^{+}$} & \multicolumn{2}{|c|}{$\begin{array}{l}\text { Subjects without allergic sensitisation anc } \\
\text { recent URI symptoms } \mathrm{s}^{\mathrm{s}}\end{array}$} \\
\hline Intercept & $1.536(1.277-1.796)$ & $<0.001$ & $1.933(1.697-2.170)$ & $<0.001$ & $1.892(1.616-2.169)$ & $<0.001$ \\
\hline Age yrs & $0.061(0.031-0.092)$ & $<0.001$ & $0.046(0.024-0.068)$ & $<0.001$ & $0.048(0.022-0.074)$ & $<0.001$ \\
\hline Allergic sensitisation $f$ & $0.299(0.162-0.435)$ & $<0.001$ & & & & \\
\hline Total $\lg E(\log ) \mathbf{k U} \cdot \mathrm{L}^{-1}$ & $0.107(0.061-0.153)$ & $<0.001$ & & & & \\
\hline Ambient nitric oxide pbb & $0.027(0.008-0.045)$ & 0.005 & & & & \\
\hline
\end{tabular}

URI: upper respiratory infection; IgE: immunoglobulin $\mathrm{E} .{ }^{\#}$ : adjusted $\mathrm{R}^{2}=0.217$ (equation 1), 0.051 (equation 2) and 0.052 (equation 3), respectively. Residual sD $=0.578$ (equation 1), 0.493 (equation 2) and 0.468 (equation 3), respectively. ${ }^{\bullet}: n=661 ;{ }^{+}: n=299 ;{ }^{\varsigma}: n=220 ;{ }^{f}$ : defined as a value of ImmunoCAP Phadiatop Infant (Phadia, Uppsala, Sweden) of $\geqslant 0.35 \mathrm{kU} \cdot \mathrm{L}^{-1} ; \#$ : compared with morning; "थ: drinking water within $1 \mathrm{~h}$ before testing. 


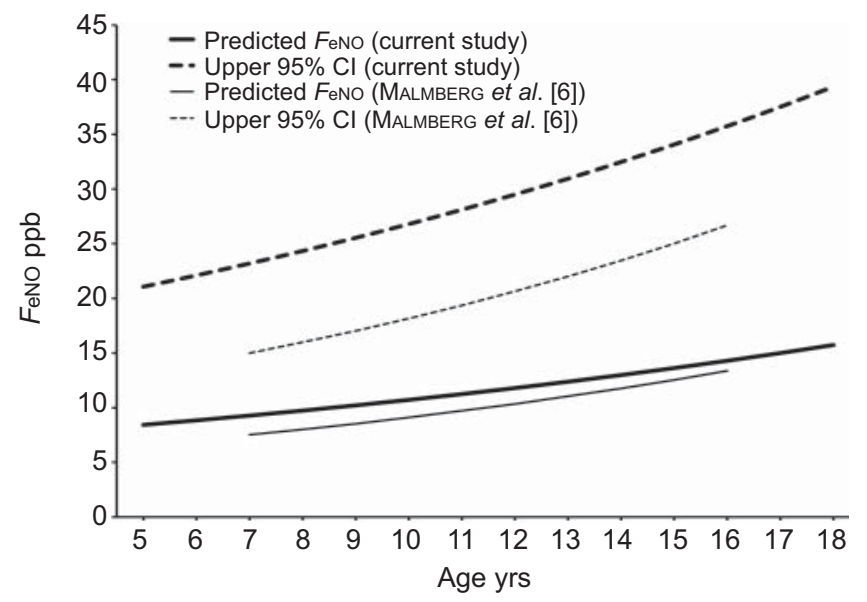

FIGURE 4. Predicted exhaled nitric oxide fraction ( $F$ eNO) values and upper 95\% $\mathrm{Cl}$ were plotted as a function of age. Data taken from MALMBERG et al. [6] in a sample of healthy nonatopic Caucasian children were included for comparison.

children in a recent population-based study [24], supporting the former observation. Therefore, it is likely that genetic factors may account for the "missing variability" of FeNO. Given that inducible $\mathrm{NO}$ synthase in squamous and respiratory epithelia produces the vast majority of the NO detected in exhaled breath in normal subjects [25], it can be speculated that ethnic differences in the genetic regulation of NO synthase pathway may explain the differences of FeNO levels between Asian and Caucasian children. In addition, the observation that Asian children in both the current population and in a previous study [26] have relatively low spirometry values has led to speculation regarding differences in lung function to explain FeNO differences between Asian and Caucasian children. This requires further investigation. There are also other possible explanations, including methodological factors, measurement conditions, heterogeneity of population and less well-recognised environmental factors, such as air pollution, especially particulate matter and ozone, type of diet, differences in oral bacterial flora and upcoming respiratory infections.

This large study demonstrates that $F$ eNO is positively associated with age, allergic sensitisation, total $\operatorname{IgE}$, ambient NO, measurements in the afternoon and drinking water, and is negatively associated with weight. Thus, factors affecting FeNO in Asian children are generally similar to those reported in Caucasian children $[6-8,10,13]$. Although the mechanism for the age dependence of FeNO is largely unknown, having the same fixed expiratory flow in all ages is a possible reason [4]. With increasing height accompanying ageing, the total airway mucosal surface area available for $\mathrm{NO}$ diffusion will increase, which will lead to higher FeNO levels using the same exhalation flow rate [27, 28]. The age-dependence of FeNO has been suggested in previous smaller studies in children [7, 29-31].

Notably, allergic sensitisation (defined as a value of ImmunoCAP Phadiatop Infant of $\geqslant 0.35 \mathrm{kU} \cdot \mathrm{L}^{-1}$ ) is an important determinant of FeNO, even in healthy children who have no history of allergic diseases and have no current or past symptoms suggestive of allergic diseases. This finding not only confirms the previously reported association of allergic sensitisation with $\mathrm{FeNO}[6,17,29,32]$ but further indicates that the association is quantitative and independent of symptoms. As such, a hypothesis is proposed here that FeNO elevation may denote a constitutional feature of allergic sensitisation. As recent evidence suggests that elevated FeNO in subjects without respiratory symptoms indicates a risk for developing asthma-like symptoms and even clinical asthma [33, 34], longitudinal follow-up of healthy children with increased FeNO is warranted.

Even though this cross-sectional study with one measurement during the daytime is not ideal for investigating the circadian rhythm of $F \mathrm{eNO}$, there is a significant trend of increased FeNO in the afternoon compared to the morning. This circadian FeNO variation in healthy children is consistent with previous findings in healthy adults $[35,36]$. However, other studies demonstrate different or no circadian FeNO patterns [30, 37]. It has been established that there is increased FeNO after ingesting nitrate or nitrate-containing foods [38, 39], while mouthwash procedures immediately before the measurement reduce such influence [38]. Thus, the rise in FeNO during the day may be attributed to dietary nitrate. However, given that the influence of dietary nitrate on FeNO reaches a maximum effect $2 \mathrm{~h}$ after ingestion [38], it can be argued that refraining from eating for $1 \mathrm{~h}$ prior to testing, which is according to the current ATS/ERS guidelines [13], may be inadequate. Taken together, it is ideal to measure FeNO at the same time during the day, to always question recent food intake and perhaps to add a mouthwash procedure immediately before measurements, particularly for longitudinal comparisons.

This study also demonstrates a small but significant negative association of weight with FeNO levels in healthy Asian children, estimated at $0.7 \%$ decrease per $\mathrm{kg}$. A similar finding of increasing weight-for-height associated with decreasing FeNO is observed in a study of offline FeNO measurement in Southern Californian children [10]. A preliminary consensus reached between our study and that of LINN et al. [10] is that the influence of weight on FeNO levels is relatively small. Moreover, although ambient NO was generally low in this study and inhalation of NO-free air was applied to all measurements, ambient NO still has a slight but significant influence on FeNO levels. It is therefore preferable, regardless of technique used, that ambient $\mathrm{NO}$ at the time of testing should be recorded and considered when interpreting FeNO levels in children. Avoiding measuring FeNO within $1 \mathrm{~h}$ after drinking fluids is recommended because the data here indicate that such behaviour significantly and independently affects FeNO.

Taken together, the reference values and determinants of FeNO in healthy Asian children established by the current study are particularly important for interpreting FeNO in children of Asian descent. The strength of this study stems from a large sample size, a wide age range, incorporation of spirometry and objective markers of atopy, application of current standards for measurement and a thorough analysis. However, it should be noted that extrapolation of the results to Asian children living in other countries and cultures still needs further confirmation.

In conclusion, the upper limits of normal for FeNO in healthy Asian children depend on age, ranging from $21 \mathrm{ppb}$ in young children to $39 \mathrm{ppb}$ in adolescents. These are $~ 9-10 \mathrm{ppb}$ higher than those measured in Caucasian children in earlier studies. Both host factors (e.g. ethnicity, age, allergic sensitisation, total IgE, weight and drinking water) and non-host factors (e.g. ambient nitric oxide and time of testing) are important determinants of FeNO in children. 


\section{SUPPORT STATEMENT}

This work was supported by Chang Gung Memorial Hospital (grants CMRPG260291, CMRPG260292 and CMRP260293).

\section{STATEMENT OF INTEREST}

None declared.

\section{ACKNOWLEDGEMENTS}

Members of the PATCH study group are: J.L. Huang (Study Coordinator), T.C. Yao, W.I. Lee, L.S. Ou, L.C. Chen and K.W. Yeh (Principal Investigators).

The authors thank the study subjects, their parents, their teachers and the school nurses, as well as the schools involved, for their active participation in the study. The authors also thank the Dept of Education, Keelung City Government, Keelung City, Taiwan for administrative support for the study, and C-J. Chang (Chang Gung Clinical Informatics and Medical Statistics Research Centre, Chang Gung University, Taoyuan, Taiwan) for providing statistical support.

\section{REFERENCES}

1 Taylor DR. Nitric oxide as a clinical guide for asthma management. J Allergy Clin Immunol 2006; 117: 259-262.

2 Smith AD, Taylor DR. Is exhaled nitric oxide measurement a useful clinical test in asthma? Curr Opin Allergy Clin Immunol 2005; 5: 49-56.

$3 \mathrm{Lim} \mathrm{KG}$, Mottram C. The use of fraction of exhaled nitric oxide in pulmonary practice. Chest 2008; 133: 1232-1242.

4 Bates CA, Silkoff PE. Exhaled nitric oxide in asthma: from bench to bedside. J Allergy Clin Immunol 2003; 111: 256-262.

5 Taylor DR, Pijnenburg MW, Smith AD, et al. Exhaled nitric oxide measurements: clinical application and interpretation. Thorax 2006; 61: 817-827.

6 Malmberg LP, Petays T, Haahtela T, et al. Exhaled nitric oxide in healthy nonatopic school-age children: determinants and heightadjusted reference values. Pediatr Pulmonol 2006; 41: 635-642.

7 Buchvald F, Baraldi E, Carraro S, et al. Measurements of exhaled nitric oxide in healthy subjects age 4 to 17 years. J Allergy Clin Immunol 2005; 115: 1130-1136.

8 Kovesi T, Kulka R, Dales R. Exhaled nitric oxide concentration is affected by age, height, and race in healthy 9- to 12-year-old children. Chest 2008; 133: 169-175.

9 2005-2009 American Community Survey 5-Year Estimates. www. factfinder.census.gov/acs/www/data_documentation/2009_5yr data/ Date last updated: December 14, 2010. Date last accessed: January 15, 2011.

10 Linn WS, Rappaport EB, Berhane KT, et al. Exhaled nitric oxide in a population-based study of southern California schoolchildren. Respir Res 2009; 10: 28.

11 Yao TC, Ou LS, Yeh KW, et al. Associations of age, gender, and BMI with prevalence of allergic diseases in children: $\mathrm{PATCH}$ study. J Asthma 2011; 48: 503-510.

12 Asher MI, Keil U, Anderson HR, et al. International Study of Asthma and Allergies in Childhood (ISAAC): rationale and methods. Eur Respir J 1995; 8: 483-491.

13 ATS/ERS recommendations for standardized procedures for the online and offline measurement of exhaled lower respiratory nitric oxide and nasal nitric oxide, 2005. Am J Respir Crit Care Med 2005; 171: 912-930.

14 Miller MR, Hankinson J, Brusasco V, et al. Standardisation of spirometry. Eur Respir J 2005; 26: 319-338.

15 Knudson RJ, Lebowitz MD, Holberg CJ, et al. Changes in the normal maximal expiratory flow-volume curve with growth and aging. Am Rev Respir Dis 1983; 127: 725-734.

16 Ballardini N, Nilsson C, Nilsson M, et al. ImmunoCAP Phadiatop Infant - a new blood test for detecting IgE sensitisation in children at 2 years of age. Allergy 2006; 61: 337-343.
17 Saito J, Inoue K, Sugawara A, et al. Exhaled nitric oxide as a marker of airway inflammation for an epidemiologic study in schoolchildren. J Allergy Clin Immunol 2004; 114: 512-516.

18 Matsunaga K, Hirano T, Kawayama T, et al. Reference ranges for exhaled nitric oxide fraction in healthy Japanese adult population. Allergol Int 2010; 59: 363-367.

19 Travers J, Marsh S, Aldington S, et al. Reference ranges for exhaled nitric oxide derived from a random community survey of adults. Am J Respir Crit Care Med 2007; 176: 238-242.

20 Olivieri M, Talamini G, Corradi M, et al. Reference values for exhaled nitric oxide (reveno) study. Respir Res 2006; 7: 94.

21 Olin AC, Bake B, Toren K. Fraction of exhaled nitric oxide at $50 \mathrm{~mL} \cdot \mathrm{s}^{-1}$ : reference values for adult lifelong never-smokers. Chest 2007; 131: 1852-1856.

22 Levesque MC, Hauswirth DW, Mervin-Blake S, et al. Determinants of exhaled nitric oxide levels in healthy, nonsmoking African American adults. J Allergy Clin Immunol 2008; 121: 396-402.

23 Lund MB, Kongerud J, Nystad W, et al. Genetic and environmental effects on exhaled nitric oxide and airway responsiveness in a population-based sample of twins. Eur Respir J 2007; 29: 292-298.

24 Salam MT, Bastain TM, Rappaport EB, et al. Genetic variations in nitric oxide synthase and arginase influence exhaled nitric oxide levels in children. Allergy 2011; 66: 412-419.

25 Hansel TT, Kharitonov SA, Donnelly LE, et al. A selective inhibitor of inducible nitric oxide synthase inhibits exhaled breath nitric oxide in healthy volunteers and asthmatics. FASEB J 2003; 17: 1298-1300.

26 Ip MS, Karlberg EM, Karlberg JP, et al. Lung function reference values in Chinese children and adolescents in Hong Kong. I. Spirometric values and comparison with other populations. Am J Respir Crit Care Med 2000; 162: 424-429.

27 Alving K, Malinovschi A. Basic aspects of exhaled nitric oxide. Eur Respir Mon 2010; 49: 1-31.

28 Pedroletti C, Hogman M, Merilainen P, et al. Nitric oxide airway diffusing capacity and mucosal concentration in asthmatic schoolchildren. Pediatr Res 2003; 54: 496-501.

29 Franklin PJ, Taplin R, Stick SM. A community study of exhaled nitric oxide in healthy children. Am J Respir Crit Care Med 1999; 159: 69-73.

30 Latzin P, Beck J, Griese M. Exhaled nitric oxide in healthy children: variability and a lack of correlation with atopy. Pediatr Allergy Immunol 2002; 13: 37-46.

31 Kissoon N, Duckworth LJ, Blake KV, et al. Exhaled nitric oxide concentrations: online versus offline values in healthy children. Pediatr Pulmonol 2002; 33: 283-292.

32 Jackson DJ, Virnig CM, Gangnon RE, et al. Fractional exhaled nitric oxide measurements are most closely associated with allergic sensitization in school-age children. J Allergy Clin Immunol 2009; 124: 949-953.

33 Olin AC, Rosengren A, Thelle DS, et al. Increased fraction of exhaled nitric oxide predicts new-onset wheeze in a general population. Am J Respir Crit Care Med 2010; 181: 324-327.

34 Bastain TM, Islam T, Berhane $\mathrm{KT}$, et al. Exhaled nitric oxide, susceptibility and new-onset asthma in the Children's Health Study. Eur Respir J 2011; 37: 523-531.

35 Stark H, Purokivi M, Kiviranta J, et al. Short-term and seasonal variations of exhaled and nasal NO in healthy subjects. Respir Med 2007; 101: 265-271.

36 Palm JP, Graf P, Lundberg JO, et al. Characterization of exhaled nitric oxide: introducing a new reproducible method for nasal nitric oxide measurements. Eur Respir J 2000; 16: 236-241.

37 Mattes J, Storm van's Gravesande K, Moeller C, et al. Circadian variation of exhaled nitric oxide and urinary eosinophil protein $X$ in asthmatic and healthy children. Pediatr Res 2002; 51: 190-194.

38 Zetterquist W, Pedroletti C, Lundberg JO, et al. Salivary contribution to exhaled nitric oxide. Eur Respir J 1999; 13: 327-333.

39 Olin AC, Aldenbratt A, Ekman A, et al. Increased nitric oxide in exhaled air after intake of a nitrate-rich meal. Respir Med 2001; 95: 153-158. 